\title{
Over-expression of Topoisomerase II Enhances Salt Stress Tolerance in Tobacco
}

\author{
Riffat John ${ }^{1 *}$, Uma Ganeshan ${ }^{2}$, Badri N. Singh ${ }^{3}$, Tanushri Kaul ${ }^{3}$, Malireddy K. Reddy ${ }^{3}$, \\ Sudhir K. Sopory ${ }^{3}$ and Manchikatla V. Rajam ${ }^{2 *}$ \\ ${ }^{1}$ Plant Molecular Biology Laboratory, Department of Botany, University of Kashmir, Srinagar, India, ${ }^{2}$ Plant Polyamine, \\ Transgenic and RNAi Laboratory, Department of Genetics, University of Delhi South Campus, New Delhi, India, ${ }^{3}$ Plant \\ Biology, International Centre for Genetic Engineering and Biotechnology, New Delhi, India
}

Topoisomerases are unique enzymes having an ability to remove or add DNA supercoils and untangle the snarled DNA. They can cut, shuffle, and religate DNA strands and remove the torsional stress during DNA replication, transcription or recombination events. In the present study, we over-expressed topoisomerase II (Topoll) in tobacco (Nicotiana tabaccum) and examined its role in growth and development as well as salt ( $\mathrm{NaCl})$ stress tolerance. Several putative transgenic plants were generated and the transgene integration and expression was confirmed by PCR and Southern blot analyses, and RT-PCR analysis respectively. Percent seed germination, shoot growth, and chlorophyll content revealed that transgenic lines over-expressing the NtTopoll $\alpha-1$ gene exhibited enhanced tolerance to salt (150 and $200 \mathrm{mM} \mathrm{NaCl}$ ) stress. Moreover, over-expression of Topoll lead to the elevation in proline and glycine betaine levels in response to both concentrations of $\mathrm{NaCl}$ as compared to wild-type. In response to $\mathrm{NaCl}$ stress, Topoll over-expressing lines showed reduced lipid peroxidation derived malondialdehyde (MDA) generation. These results suggest that Topoll plays a pivotal role in salt stress tolerance in plants.

Keywords: tobacco, topoisomerase II, transgenic plants, salinity stress, stress tolerance, glycine betaine

\section{INTRODUCTION}

Unwinding of the DNA double helix is either transient as in transcription and recombination or stable as during DNA replication (Champoux, 2001). DNA being negatively supercoiled, the strand separation by helicases first relaxes DNA but further duplex melting leads to positively supercoiled strands that impede the action of helicases (Capranico et al., 2010). Topoisomerases ubiquitously present in both prokaryotes and eukaryotes play a crucial role in untangling and relaxing the interwound DNA supercoiled duplex, thereby mitigating the topological stress (Vos et al., 2011; Ashour et al., 2015). Topoisomerases remarkably cut, shuffle and rejoin DNA strands and are pre-requisite for proper chromosomal organization and segregation (Nitiss, 2009).

DNA topoisomerase was first isolated from Escherichia coli by James Wang in 1971 and was named as $\omega$ protein now known as DNA topoisomerase I (TopoI; Wang, 1971). Toposiomerases are extraordinarily diverse and quiet complex in their mode of action and divided into two categories: Type I and type II (Singh et al., 2003, 2004; Vrielynck et al., 2016). Type I topoisomerases are ATP independent-monomeric proteins which nick and seal only one strand of DNA thus changing the linking number of supercoiled DNA by steps of one, whereas the type II topoisomerases are 
ATP-dependent involved in nicking both strands of DNA to create a staggered double-strand break and thereby changing the linking number by steps of two (Pyke et al., 1989; Hsieh, 1990).

Topoisomerase II (TopoII), a dimeric enzyme, is located at the base of the chromosomal DNA loops that changes the topology of DNA by nicking two strands of DNA to form a gate, then directing another DNA molecule to pass through the gate and finally resealing the nicks to close the gate (Tammaro et al., 2016). In addition, TopoII plays a role in removing positive superturns ahead of replication forks and moving transcription complexes in archaea and bacteria, since the TopoIA present in these two domains cannot relax positive superturns (Gadelle et al., 2003). All eukaryotic type II topoisomerases characterized till now show similarity in their primary structure comprising of 1429-1530 amino acid residues with a predictable molecular mass of 160-170 $\mathrm{kDa}$ (Wang, 2002; Corbett and Berger, 2004). In the recent past, there has been a surge in biochemical and biological aspects of topoII and various processes underlying its functions and reactions have been established (Nitiss, 2009; Blattner, 2016) but studies are mostly restricted to animal system. TopoII has been extensively studies in animals not only with reference to change in DNA topology but with respect to a large number of topoisomerase-targeted drugs that have been identified possessing antimicrobial and anticancerous activities (Kathiravan et al., 2013; Ashour et al., 2014). Most of these drugs interfer with the processing of the DNA break, causing stabilization of transient covalent DNA-DNA topoisomerase complex into a form that is harmful for the cell (Gadelle et al., 2003).

Abiotic stress tolerance is a multigenic trait. Although large number of genes have been identified in plants in response to abiotic stress but unraveling the relationship between DNA replication enzymes and abiotic stress is crucial for developing abiotic stress tolerant transgenic crops (Hettiarachchi et al., 2005). Earlier, we have isolated and characterized TopoII from Nicotiana tabacum. We proposed that TopoII under GAL1 promoter functionally complements a temperature-sensitive topoisomerase $\mathrm{II}^{\text {ts }}$ yeast mutant (Singh et al., 2003) and its transcript levels get up-regulated in response to cold and salinity stress in tobacco and pea (Hettiarachchi et al., 2005). Here, we report that over-expression of TopoII in N. tabaccum leads to enhanced salinity stress tolerance.

\section{MATERIALS AND METHODS}

\section{Transformation of Agrobacterium}

Recombinant plasmid pBI121- NtTopII $\alpha$-1 was transferred into Agrobacterium by freeze-thaw method. Competent cells were prepared by growing Agrobacterium tumefaciens (LBA4404) in $50 \mathrm{ml}$ YEM medium (0.04\% yeast extract, $1 \%$ mannitol, $0.01 \%$ $\mathrm{NaCl}, 0.02 \% \mathrm{MgSO}_{4} .7 \mathrm{H}_{2} \mathrm{O}$ and $0.05 \% \mathrm{~K}_{2} \mathrm{HPO}_{4}$ ) at $28^{\circ} \mathrm{C}$ with vigorous shaking until $0.5 \mathrm{OD}_{600}$ was achieved. Later, the culture was chilled on ice and then centrifuged at $3000 \mathrm{x}$ g for $5 \mathrm{~min}$ at $4^{\circ} \mathrm{C}$. After suspending the pellet in $1 \mathrm{ml}$ of ice cold $\mathrm{CaCl}_{2}(20$ $\mathrm{mM}), 0.1 \mathrm{ml}$ aliquots were dispensed in pre-chilled Eppendorf tubes and stored at $-80^{\circ} \mathrm{C}$.

\section{Agrobacterium-Mediated Tobacco Transformation}

Tobacco seeds (N. tabaccum, cv Petit Havana) were sterilized by soaking in a bleach solution $(2 \% \mathrm{w} / \mathrm{v})$ for $15-20 \mathrm{~min}$ followed by three washes in sterile water. Seeds were germinated on RM (rooting medium) (Macro nutrients: $1.9 \mathrm{~g} \mathrm{KNO}_{3}$, $0.37 \mathrm{~g} \mathrm{MgSO}_{4} .7 \mathrm{H}_{2} \mathrm{O}, 0.44 \mathrm{~g} \quad \mathrm{CaCl}_{2} .2 \mathrm{H}_{2} \mathrm{O}, 0.17 \mathrm{~g} \quad \mathrm{KH}_{2} \mathrm{PO}_{4}$, $1.65 \mathrm{~g}\left(\mathrm{NH}_{4}\right)_{2} \mathrm{NO}_{3}$; Micro nutrients: $1.6 \mathrm{mg} \mathrm{MnSO}_{4} .2 \mathrm{H}_{2} \mathrm{O}$, $0.62 \mathrm{mg} \mathrm{H} \mathrm{H}_{3} \mathrm{BO}_{3}, 0.86 \mathrm{mg} \mathrm{ZnSO} \mathrm{Zn}_{4} .7 \mathrm{H}_{2} \mathrm{O}, 0.83 \mathrm{mg} \mathrm{KI}, 0.025 \mathrm{mg}$ $\mathrm{Na}_{2} \mathrm{MoO}_{4} .2 \mathrm{H}_{2} \mathrm{O}, \quad 0.0025 \mathrm{mg} \quad \mathrm{CuSO}_{4} .5 \mathrm{H}_{2} \mathrm{O}, \quad 0.0025 \mathrm{mg}$ $\mathrm{CoCl}_{2} .6 \mathrm{H}_{2} \mathrm{O} ; 50 \mathrm{mg}$ Fe-EDTA, $30 \mathrm{~g}$ Sucrose and 6\% agar per liter, $\mathrm{pH}$ 5.8) and kept under moderate light, temperature, and low humidity conditions till plants with healthy leaves were produced. Uniform sized leaves were harvested and leaf discs were prepared by cutting the leaves into small squares $\left(1 \mathrm{~cm}^{2}\right)$. The leaf discs were then immersed in Agrobacterium cells [1:10 dilution of overnight grown culture in liquid RMOP (MS containing $1 \mathrm{mg} / \mathrm{L}$ benzyladenine (BAP), 3\% sucrose, and 7 $\mathrm{g} / \mathrm{l}$ phytoagar)] for $5 \mathrm{~min}$ harboring recombinant vector $\mathrm{pBI} 121$ NtTopII $\alpha-1$ for TopoII gene under the control of CaMV35S promoter and nopaline synthase terminator, and $n p t$-II gene as plant selection marker. Leaf discs were taken out, blot dried and placed upside down on the RMOP culture plates. The explants were allowed to co-culture with Agrobacterium for 2-3 days. Immediately after co-cultivation, explants were transferred to RMOP medium (RM supplemented with $1 \mathrm{mg}$ thiamine, $1 \mathrm{mg}$ NAA, $1 \mathrm{mg}$ BAP, and $100 \mathrm{mg}$ inositol) containing $200 \mu \mathrm{g}$ kanamycin and $500 \mu \mathrm{g} / \mathrm{ml}$ carbenicillin. After 3-4 weeks, shoots with a defined stem were removed carefully from explants and placed on MS rooting medium. Following rooting, plantlets were removed from culture jars and rinsed in water and planted in pots containing vermiculite. Pots were covered with plastic bags (with pin holes) and closed tightly to retain humidity. After 7-10 days, the bags were removed in order to reduce the humidity gradually until plants became acclimatized to the ambient humidity. Thereafter, the plants were transferred to soil and grown under green-house condition to allow blooming and seed setting.

\section{Screening of Putative Tobacco Transgenic Plants by PCR Analysis}

Genomic DNA was isolated from leaf tissue of tobacco transformants and untransformed plants by CTAB method (Doyle and Doyle, 1990). The putative transgenic plants were analyzed by PCR for the integration of TopoII and nptII transgenes. The conditions for PCR were 40 cycles of denaturation at $94^{\circ} \mathrm{C}$ for $1 \mathrm{~min}$, annealing for $1 \mathrm{~min}$ at $52^{\circ} \mathrm{C}$, annealing for $1 \mathrm{~min}$ at $54^{\circ} \mathrm{C}$ for $n p t$-II gene, while $65^{\circ} \mathrm{C}$ for TopoII gene and synthesis at $72^{\circ} \mathrm{C}$ for $2 \mathrm{~min}$, and finally the extension step of $10 \mathrm{~min}$ at $72^{\circ} \mathrm{C}$. The PCR products were checked on $1 \%$ agarose gel with the ladder. The primer pairs for the amplification of a $675 \mathrm{~kb}$ fragment of $n p t$-II gene were - $5^{\prime}$ CCCATGAAAAAG CCTGGACTCACCGCG3' and 5' GCAGGCTCCCGTTTCCTT ATCGAT3'. Primer pairs specific for the amplification of a $960 \mathrm{~kb}$ fragment for TopoII gene were 5' CTGCCCAAAGAAGAAACA GG $3^{\prime}$ - and $5^{\prime}$ AACCAAAAGCCAGAGGAGGTC $3^{\prime}$. 


\section{Southern Analysis}

Genomic DNA (10 mg) from PCR positive transgenic plants and wild-type plants of tobacco was restricted with XhoI for checking the transgene integration and copy number and probed with $n p t$ II gene. Southern blots were prepared by standard procedure (Sambrook et al., 1989) using Hybond-N Nylon membrane (Pharmacia). The $n p t$-II gene probe was prepared using ${ }^{32} \mathrm{P}$ labeled dCTP by nick translation as per the manufacture's guidelines (Gibco-BRL). Hybridization was carried out for 18-24 $\mathrm{h}$ at $65^{\circ} \mathrm{C}$. The membrane was washed and then exposed to X-ray film (XK-5Kodak film).

\section{RNA Extraction and Semi-Quantitative RT-PCR Analysis}

Total RNA was isolated as per the protocol described by Chomczynski and Sacchi (1987). RT-PCR was done to check the level of transcription of the transformed lines of tobacco. Total RNA at the concentration of $1.5 \mathrm{mg}$ (treated with RNasefree DNase) was used as a template and was mixed with $1 \mathrm{X}$ buffer, 1X Q solution, $400 \mathrm{mM}$ of dNTPmix, $1.2 \mathrm{mM}$ primers, $5 \mathrm{U}$ of RNase inhibitor, and $2 \mathrm{ml}$ of enzyme mix (Reverse Transcriptase and Taq Polymerase). The reaction volume was made to $25 \mathrm{ml}$ and incubated at $50^{\circ} \mathrm{C}$ for $30 \mathrm{~min}$. After reverse transcription, the reaction mixture was heated to $95^{\circ} \mathrm{C}$ for $15 \mathrm{~min}$ (to activate HotStart Taq DNA polymerase and to simultaneously inactivate the reverse transcriptase), followed by 30 cycles of 1 min denaturation at $94^{\circ} \mathrm{C}$, primer annealing at $65^{\circ} \mathrm{C}$ for $1 \mathrm{~min}$, extension at $72^{\circ} \mathrm{C}$ for $1 \mathrm{~min}$ and final extension for $10 \mathrm{~min}$. The PCR products were analyzed on $1 \%$ agarose gel. Densitometric analysis of protein bands was performed using the public software ImageJ 1.41o developed by Wayne Rasband at the National Institutes of Health.

\section{Transgene Segregation}

One hundred $\mathrm{T}_{1}$ seeds obtained from primary transgenic plants of TopoII were used for the segregation of the transgenes. The surface sterilized seeds were inoculated on to MS basal medium supplemented with $200 \mathrm{mg} / \mathrm{l} \mathrm{kanamycin}$ and incubated at $26^{\circ} \mathrm{C} \pm$ 1 and $16 \mathrm{~h}$ photoperiod. The germination was observed up to 10 days and the percentage germination was scored for segregation analysis after 1 month. The experiment was repeated thrice.

\section{Seed Germination, Seedling Growth, Leaf Disc Assay, and Chlorophyll Content}

Fifty seeds from control and $\mathrm{T}_{1}$ transgenic lines were surfacesterilized and inoculated on to MS basal medium supplemented with $150 \mathrm{mM}$ and $200 \mathrm{mM} \mathrm{NaCl}$ for salt tolerance assays. Tolerance was based on percent seed germination. Kanamycin resistant $12 \mathrm{~T}_{1}$ seedlings with a well-developed root system were grown in culture bottles containing vermiculite: Soil (1:1) mix. The medium was supplemented with $200 \mathrm{mM} \mathrm{NaCl}$ for salt stress for 10-15 days. The tolerance was based on the survival and growth of the seedlings under stressed condition. Healthy leaves from wild-type and $\mathrm{T}_{1}$ transgenic tobacco plants (of similar age) were washed in deionized water, and 12 leaf discs of 1 $\mathrm{cm}$ diameter were punched out with cork borer and floated in a solution of $\mathrm{NaCl}(150 \mathrm{mM}$ and $200 \mathrm{mM})$ or sterile distilled water (which served as experimental control) in petridishes. The chlorophyll content was measured as per Arnon (1949). The experiments were repeated thrice with similar samples.

\section{Estimation of Proline, Lipid Peroxidation, and Glycine Betaine Content}

The kanamycin resistant $\mathrm{T}_{1}$ seedlings were grown in pots with vermiculite and soil mix (1:1) under controlled growth conditions. The seedlings were watered with $1 / 10 \mathrm{MS}$ medium with two different concentrations of $\mathrm{NaCl}$, i.e., $150 \mathrm{mM}$ and 200 $\mathrm{mM}$. Plants were grown for a period of 1 month and harvested for different assays. Free proline in leaf tissue was assayed following the protocol of Bates et al. (1973). The level of lipid peroxidation was measured by estimating MDA, using thiobarbituric acid (TBA) as the reactive material following the method of Heath and Packer (1968). Glycine betaine content in fresh leaf samples was measured according to Grieve and Grattan (1983). The absorbance was measured by spectrophotometer at $365 \mathrm{~nm}$ while glycine betaine (50-200 mg/ml) prepared in $1 \mathrm{~N} \mathrm{H}_{2} \mathrm{SO}_{4}$ was used as control. The experiments were done in triplicates and repeated thrice.

\section{Statistical Analyses}

Data were analyzed by SPSS 16.0 (SPSS Corp., Chicago, IL, USA) and subjected to statistical analysis of variance (ANOVA) with lines (One way ANOVA) and lines and treatments (Two-way ANOVA) as factors, followed by Tukey's test and least significant difference (LSD) test. A $P$-value less than 0.05 were considered statistically significant. All experiments were carried out three times.

\section{RESULTS}

\section{Tobacco Transformation, Regeneration, and Morphology}

The co-cultivated explants with TopoII gene construct showed shoot regeneration after 8-13 days of culture on the selection medium. The transformation frequency, calculated as number of explants surviving and showing shoot regeneration on selection medium upon the total number of explants co-cultivated, was in the range of $24-37 \%$. We observed that TopoII putative transgenic plants were morphologically different from control plants and showed early flowering and seed setting by 2-3 weeks. The TopoII expressing $\mathrm{T}_{0}$ and $\mathrm{T}_{1}$ transgenic lines had longer stems and robust root system as compared to the wild-type (WT) plants. Moreover, transgenics had thinner stem (reduced girth) and longer internodes. We observed about $12 \%$ increase in stem height and $11-13 \%$ internode length in tobacco transgenic plants. Interestingly stem thickness was reduced from $1.98 \mathrm{~cm}$ in control to $1.73 \mathrm{~cm}$ in transgenic lines (Figure 1, Table 1).

\section{Transgene Integration and Expression}

PCR analysis of TopoII expressing transgenic tobacco plants with screening primers specific to $n p t$-II gene confirmed the transgene integration. The PCR positive plants were analyzed by Southern hybridization for revealing the copy number of transgene. Genomic DNA of TopoII transgenics was restricted with EcoRI 


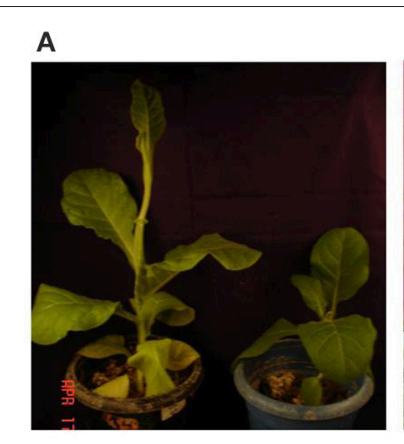

Topo II

(line A)

WT

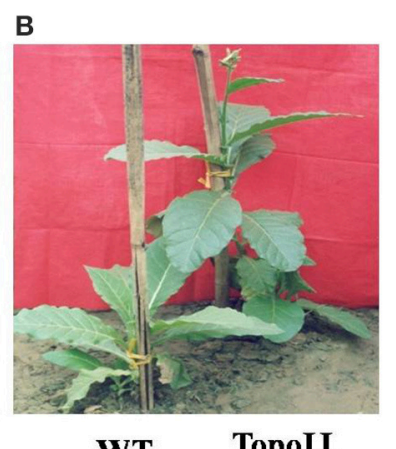

WT

TopoII

(line E)

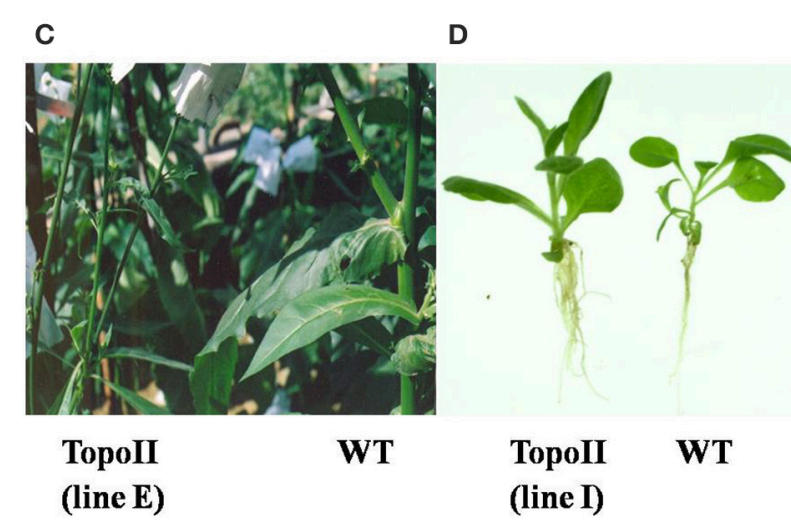

FIGURE 1 | Morphological changes in Topoll transgenic tobacco lines at different growth stages in comparison to WT. (A,B) Pre-flowering stage; (C) Post-flowering stage and (D) Longer and profuse root growth in transgenic lines as compared to WT.

and BamHI separately and probed with GUS gene. The transgenic plants had single and multiple copy transgene insertionss. The transgene expression was analyzed in different transgenic lines by semi-quantitative RT-PCR using TopoII gene-specific primers and they exhibited variable expression of transgene in different lines (Figure 2).

\section{Segregation of the Transgene}

The $\mathrm{T}_{1}$ seeds obtained from primary transgenic plants were analyzed for the segregation of the transgene on solid MS basal medium supplemented with $200 \mathrm{mg} / \mathrm{l}$ kanamycin. The transgenic seeds germinated within 10 days of inoculation and showed segregation for the transgene on kanamycin-amended medium. The control seeds failed to germinate on kanamycin containing medium. The transgenic lines having a single copy of the transgene segregated in 3:1 ratio, while other lines containing multiple transgene integrations showed deviation from this ratio (data not shown).

\section{Salt Stress Response of Transgenic Lines}

The seeds of $\mathrm{T}_{1}$ generation of transgenic TopoII tobacco lines obtained from self-pollinated primary transformants were checked for salt tolerance on the basis of seed germination, bleaching of leaf discs, and chlorophyll content under salt stress
TABLE 1 | Morphological changes in tobacco due to over-expression of Topoll gene.

\begin{tabular}{lccc}
\hline Transgenic line & \multicolumn{3}{c}{ Morphological parameters } \\
\cline { 2 - 4 } Line & $\begin{array}{c}\text { Stem height } \\
\text { (cm) }\end{array}$ & $\begin{array}{c}\text { Stem thickness } \\
\text { (cm) }\end{array}$ & $\begin{array}{c}\text { Internode length } \\
\text { (cm) }\end{array}$ \\
\hline WT & $55.21 \pm 2.12$ & $1.98 \pm 0.08$ & $0.25 \pm 0.01$ \\
A line & $75.54 \pm 3.43$ & $1.69 \pm 0.03$ & $0.36 \pm 0.01$ \\
D line & $77.24 \pm 4.27$ & $1.72 \pm 0.02$ & $0.38 \pm 0.03$ \\
E line & $76.56 \pm 4.88$ & $1.74 \pm 0.05$ & $0.37 \pm 0.02$ \\
F line & $77.38 \pm 3.13$ & $1.80 \pm 0.03$ & $0.38 \pm 0.01$ \\
I line & $40.51 \pm 2.51^{*}$ & $2.12 \pm 0.01^{*}$ & $0.20 \pm 0.01^{*}$ \\
\hline
\end{tabular}

Data are the mean and standard error, based on $12 T_{1}$ progeny of Topoll expressing transgenic lines. *Significant at 5\%. WT, wild-type.

under both in vitro and in vivo growth conditions. We examined the effect of salt stress on germination of seeds from WT and transgenic lines. The surface-sterilized transgenic as well as WT seeds were inoculated on the solid MS basal medium containing $150 \mathrm{mM}$ or $200 \mathrm{mM} \mathrm{NaCl}$. The seeds from WT exhibited about $50 \%$ germination but TopoII transgenic lines showed $100 \%$ seed germination at $150 \mathrm{mM} \mathrm{NaCl}$. At $200 \mathrm{mM} \mathrm{NaCl}$, most of the seeds from transgenic lines germinated but the seeds from WT plants could not germinate under salt stress (Figures 3A,B, Table 2). The transgenic plants of tobacco, growing in vermiculite:sand supplemented with $200 \mathrm{mM}$ for 25 days survived and showed better growth, but WT plants could not survive (Figure 3C).

The incubation of the leaf discs from WT and TopoII transgenic lines in 150 and $200 \mathrm{mM} \mathrm{NaCl}$ revealed an early bleaching of WT leaf discs as compared to transgenic lines. TopoII over-expressing lines of tobacco retained chlorophyll pigment at both 150 and $200 \mathrm{mM} \mathrm{NaCl}$ to a significant level as compared to control (Figures 4A,B).

\section{Over-expression of Topoll Leads to the Elevation in Proline and Glycine Betaine Levels and Reduction in Lipid Peroxidation}

A significant increase in proline as well as glycine betaine content was recorded in transgenic lines under 150 and $200 \mathrm{mM}$ salt stress. This suggests that up-regulation of topoisomrerase II activity leads to the stress tolerance by inducing proline and glycine betaine accumulation, while reducing the lipid peroxidation which was evident by reduced MDA content in the transgenic tobacco plants as compared to WT (Figure 5).

\section{DISCUSSION}

Apart from the role of topoisomerases in resolving problems associated with topological strains, they are being actively studied for their role as target for anticancerous drugs (Vann et al., 2016). In plants, most of the work on topoisomerases is focused on their isolation, purification and characterization (Badaracco et al., 1983) but their role in conferring abiotic stress tolerance in plants has not been explored. 
A

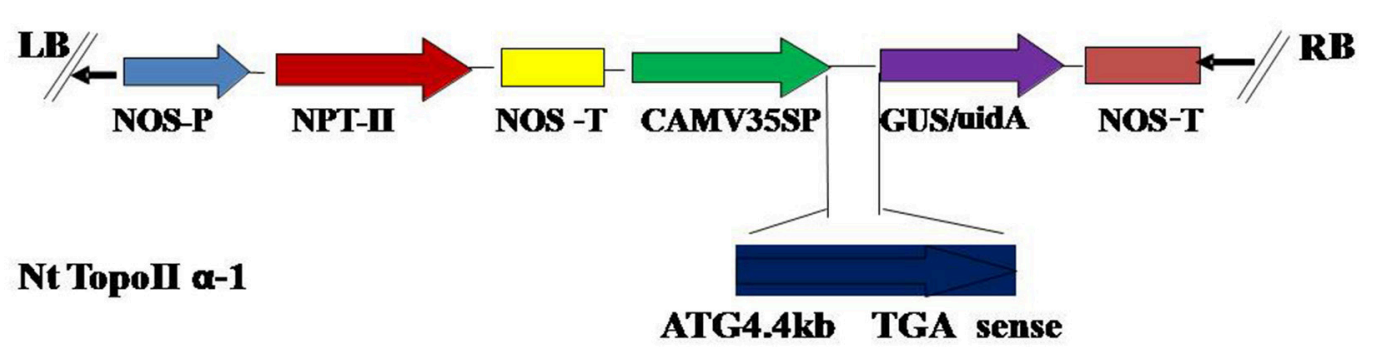

pB1121-Nt TopoHa-1

ATG4.4kb TGA sense

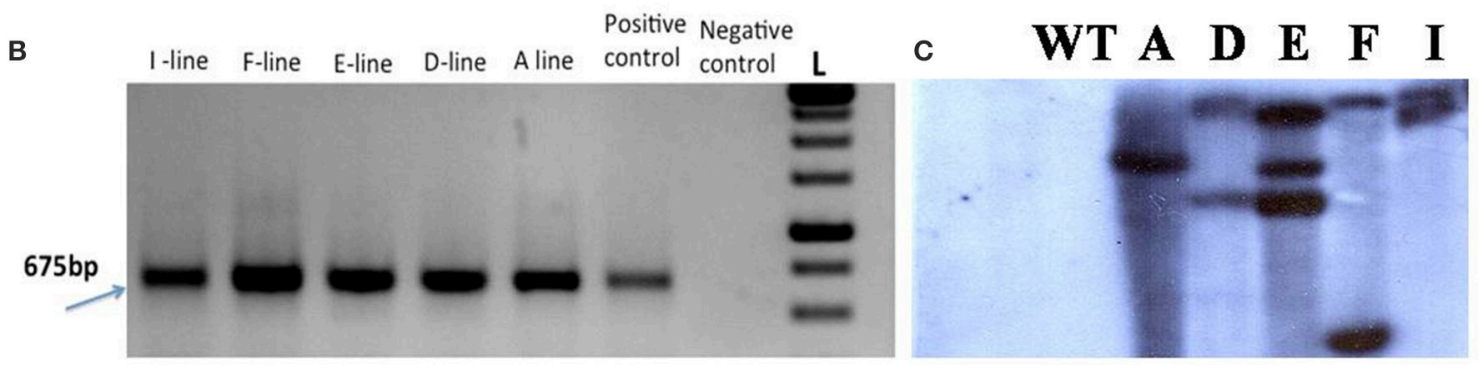

D
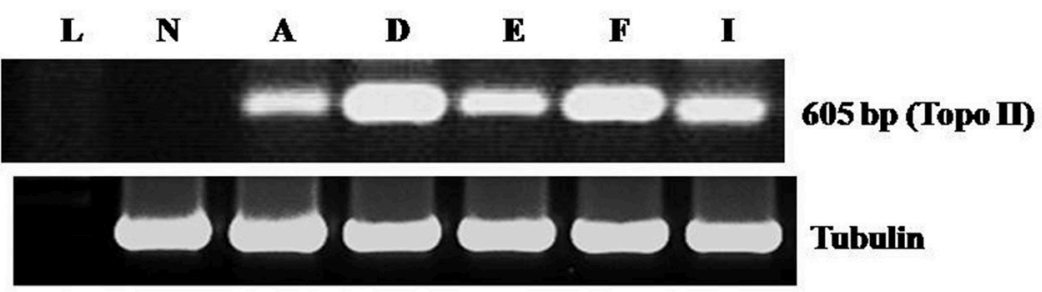

Tubulin

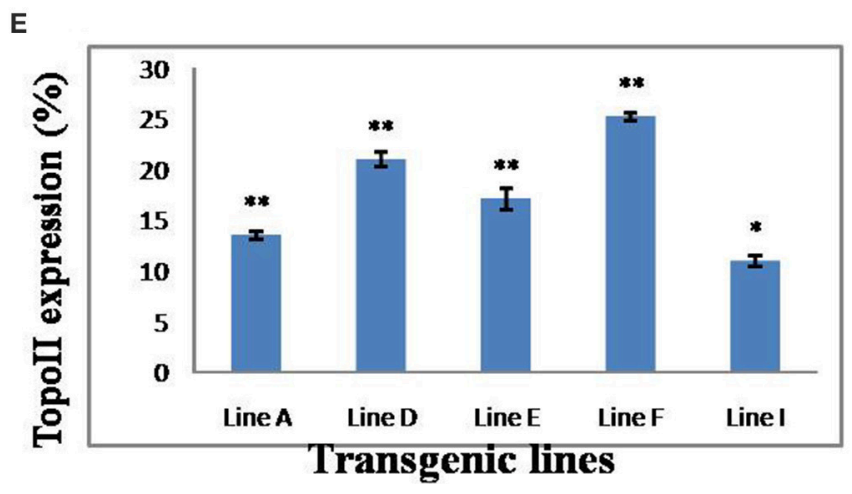

FIGURE 2 | (A) T-DNA map of NtTopoll $\alpha-1$ construct used for tobacco transformation. NOS P, nopaline synthase promoter; NPT-II, neomycin phosphotransferase II; NOS T, nopaline synthase terminator; CaMV P, Cauliflower mosaic virus $35 \mathrm{~S}$ promoter; GUS uidA, $\beta$-glucaronidase; (B) Genomic DNA PCR analysis of untransformed control and putative Topoll transgenic tobacco plants (A-l lines) using npt-Il gene-specific primers. L, DNA Ladder; Positive control, Plasmid DNA; Negative control, DNA from untransformed tobacco plant; (C) Southern blot analysis of transgenic and wild-type (WT) tobacco plants determining the T-DNA copy number. Genomic DNA was digested with Xhol, separated by electrophoresis on a $1 \%$ agarose gel and transferred onto a nylon membrane. The transferred DNA was hybridized with the npt-II gene probe labeled with $\alpha$-32P dCTP. UT, DNA from the untransformed tobacco plant, A-I, transgenic lines; (D) Transgene expression (transcript) levels quantified by RT-PCR. Tubulin was used as an internal control. L, DNA ladder; N, Blank; A-I, transgenic lines; (E) The histograms represent the average of gene expression measured with the Image J, densitometry software. Values are the means of 3 replicates with the corresponding standard error. Bars labeled with asterisks show significant differences from that of WT at ${ }^{*} P<0.05$ or ${ }^{* *} P<0.01$ by $t$-test. 
A

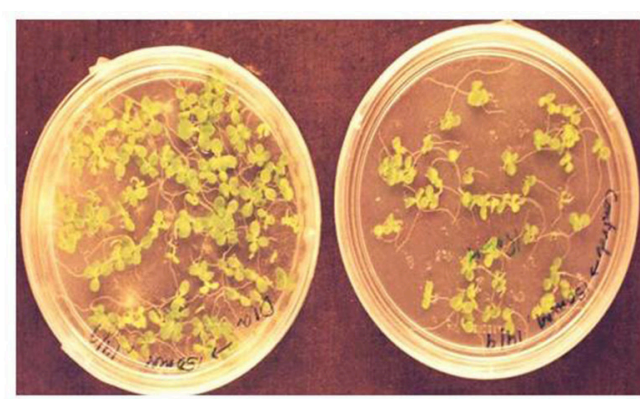

TopoII

$\mathrm{F}$ line

B

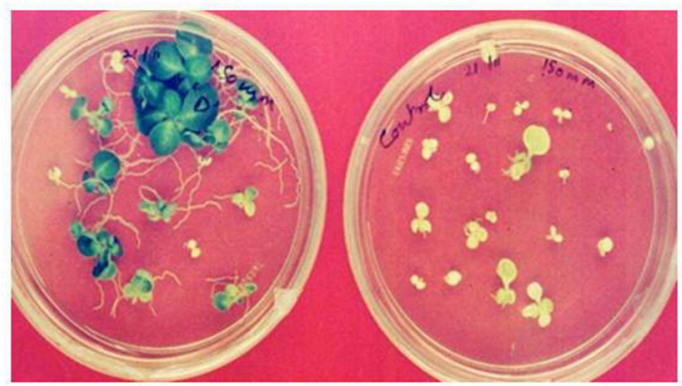

TopoII A line

C

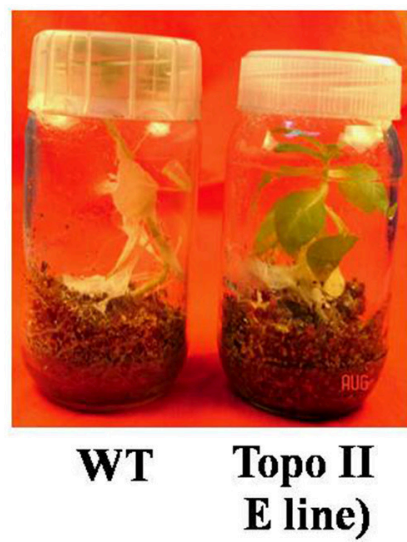

FIGURE 3 | Enhanced tolerance to different salt concentrations in Topoll over-expressing tobacco transgenic lines as compared to WT.

(A) Germination on MS medium supplemented with 150 mM; (B) Germination on MS medium supplemented with $200 \mathrm{mM} \mathrm{NaCl}$ and (C) Growth on vermiculite: Soil with $200 \mathrm{mM} \mathrm{NaCl}$.

In order to study the role of TopoII during salt stress in plants, it was over-expressed in tobacco. The transgenic tobacco plants over-expressing NtTopoI $\alpha$ showed altered plant morphology with longer stem and internode length but reduced girth as compared to WT tobacco plants. Such results corroborate with the observation by Takahashi et al. (2002), who reported that TOP $1 \alpha$ mutation in Arabidopsis leads to the abnormal morphological pattern such as changes in number of floral primodia and internode length. TopoII has
TABLE 2 | Germination of wild-type and $T_{1}$ transgenic seeds of tobacco on MS basal medium amended with 150 and $200 \mathrm{mM} \mathrm{NaCl}$ for salt stress tolerance.

\begin{tabular}{lccccccc}
\hline $\begin{array}{l}\text { Conc. of } \\
\text { NaCl used } \\
\text { (mM) }\end{array}$ & $\begin{array}{c}\text { Total no. of } \\
\text { seeds } \\
\text { inoculated }\end{array}$ & \multicolumn{5}{c}{ No. of seeds germinated } \\
\cline { 3 - 7 } & WT & A line & D line & E line & F line & I line \\
\hline 150 & 50 & 23 & 45 & 48 & 48 & 46 & 49 \\
200 & 50 & 0 & 40 & 43 & 42 & 41 & 45 \\
\hline
\end{tabular}

Data are average of percent seed germination in control and Topoll transgenic tobacco lines. The experiment was repeated thrice with fifty $T_{1}$ seeds of Topoll expressing transgenic lines in each experiment.

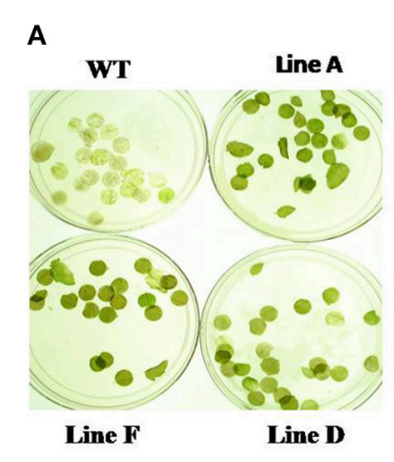

B

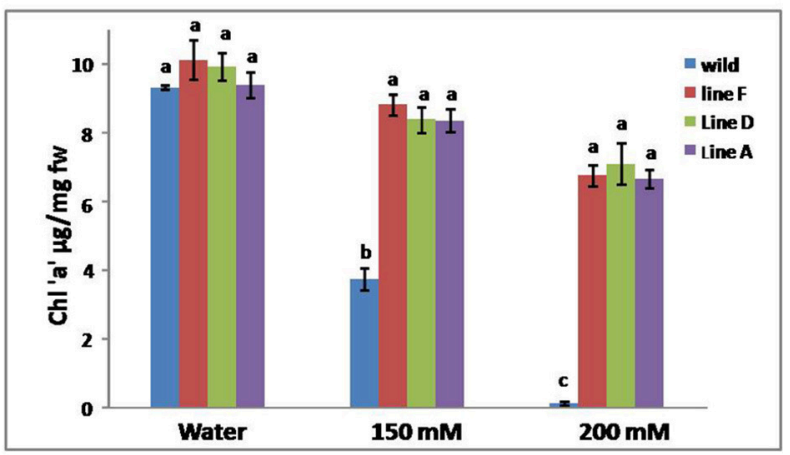

NaCl Treatment

FIGURE 4 | (A) Leaf disc assay for chlorophyll loss in WT and transgenic lines after $150 \mathrm{mM} \mathrm{NaCl}$ treatment and (B) Chlorophyll estimation after leaf disc assay with WT and Topoll over-expressing tobacco transgenic lines under salinity stress condition. Bars represent means and standard errors $(n=3)$ and those noted with same letters are not significantly different at $P<0.05$ by Tukey's test.

also been implicated in root stem cell niche maintainence in Arabidopsis thalliana (Yu et al., 2016). Our studies show that TopoII over-expression alters the morphology of the plants and these results suggest that topoisomerases play a critical role in regulating the developmental pattern in plants. Yin et al. (2002) also observed that mutation in TopoVI and TopoVIB homologs leads to pleiotropic dwarf phenotypes in Arabidopsis. Recently, we also reported that TopoI silencing in tobacco leads to the developmental abnormalities (Singh et al., 2015). 

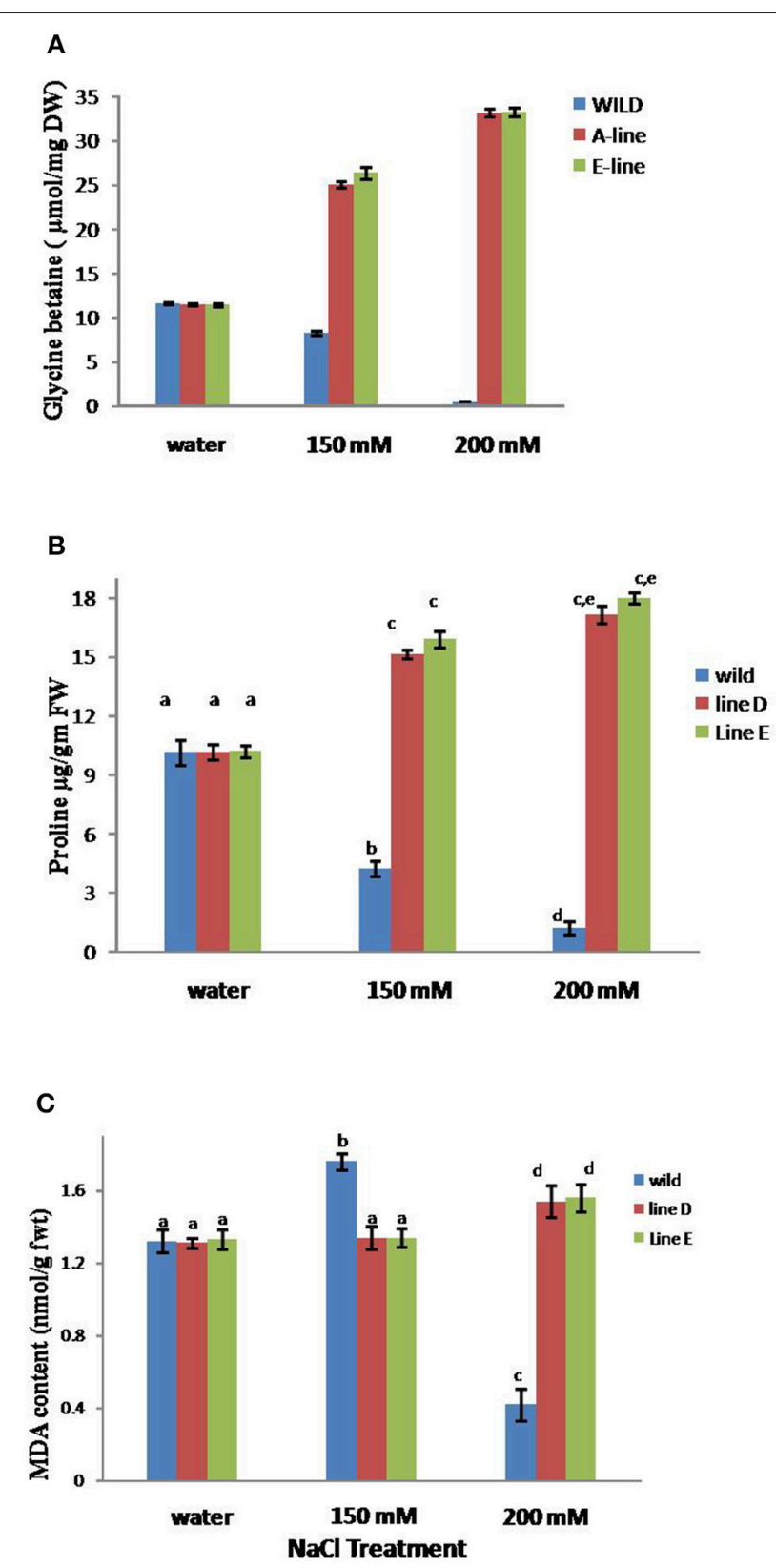

FIGURE 5 | Content of glycine betaine (A), proline (B), and MDA (C) in Topoll over-expressing tobacco and WT lines after treatment with 150 and $200 \mathrm{mM} \mathrm{NaCl}$. Bars represent means and standard errors $(n=3)$ and those noted with same letters are not significantly different at $P<0.05$ by Tukey's test.

The leaf disc assay showed that tobacco plants with TopoII over-expression exhibited lesser loss of chlorophyll as compared to WT after putting them in 150 and $200 \mathrm{mM} \mathrm{NaCl}$. Although the TopoII transgenic plants showed retention of chlorophyll but leaf discs from the WT showed complete bleaching. The decrease in chlorophyll content may be due to an increase of chlorophyll degradation as chlorophyllase activity under high salt concentration as seen in sunflower leaves (Santos, 2004). Also, Toposomerases may have role in chloroplast DNA replication as Marrison and Leech (1992) observed by localizing TopoII in chloroplast of wheat leaf that TopoII is associated with effective replication of chloroplast DNA.

We evaluated the TopoII expressing tobacco plants for biochemical parameters associated with $\mathrm{NaCl}$ stress such as the accumulation of proline, glycine betaine, and MDA content. A significant increase in the proline levels in $\mathrm{NaCl}$ tolerant transgenic lines was observed in comparison to WT and increase being higher when treated with $200 \mathrm{mM}$ as compared to 150 $\mathrm{mM} \mathrm{NaCl}$. The proline content significantly elevated by 56 and $60 \%$ in transgenic lines A and E respectively. Higher free proline levels in response to salinity have been studied in different plants and possible roles of proline has been cited such as an osmolyte, stabilizing proteins, regulating cytosolic $\mathrm{pH}$, and scavenging of hydroxyl radicals (Koca et al., 2007; Hazman et al., 2015; Dar et al., 2016). Glycine betaine levels also elevated in response to salt stress in transgenic lines by approximately $125 \%$ in both the transgenic lines when compared with WT. Various studies done at physiological level as well as genetics have verified that the levels of accumulated glycine betaine are proportional to the degree of salt tolerance (Sakamoto and Murata, 2002; Lai et al., 2014; Choi et al., 2016). Moreover, an exogenous supply of glycine betaine also increases the salt tolerance of some plants that are otherwise unable to accumulate glycine betaine (Hasanuzzaman et al., 2014). Glycine betaine effectively stabilizes the quaternary structures of enzymes and complex proteins, and maintains the highly ordered state of membranes under salinity stress (Chen and Murata, 2008). Also, glycine betaine is part of different signaling pathway which leads to salt stress tolerance via the activation of different stress related genes (Türkan and Demiral, 2009). Salt stress is known to cause lipid peroxidation, which has often been used as an indicator of salt-induced oxidative damage in membranes (Hernández and Almansa, 2002). On the contrary, we observed that MDA content was unaffected in salt stressed leaves of TopoII expressing transgenic lines in comparison to leaves of WT, which showed significant enhancement in response to $\mathrm{NaCl}(150 \mathrm{mM})$. In response to $200 \mathrm{mM} \mathrm{NaCl}$, MDA levels were slightly higher in transgenic lines in comparison to $150 \mathrm{mM} \mathrm{NaCl}$, but drastically reduced in WT. Results indicated that the over-expression of TopoII gene conferred enhanced tolerance to salt induced oxidative stress. Topoisomerases play a role in integration of multiple ROS signals released by plants in response to environmental stress (Šimková et al., 2012).

\section{CONCLUSION}

Our study reveals that NtTopoII1- $\alpha$ over-expression in tobacco confers salt stress tolerance to the transformed lines as compared to wild-type plants. TopoII over-expression changed the morphology of the transgenic plants and improved the seed germination on salt supplemented medium. The transgenic lines also displayed higher levels of chlorophyll, proline, and glycine betaine under $\mathrm{NaCl}$ salt stress. Plants utilize different strategies to efficacously combat the adverse environmental conditions (e.g., salinity, drought, extreme temperatures, heavy-metal stress, etc.). 
Thus, in-depth analyses of the numerous roles of different types of helicases/topoisomerases in stress adaptation would prove beneficial for developing stress tolerant crops in future.

\section{AUTHOR CONTRIBUTIONS}

SS and MVR conceived the experiments. RJ, UG, and BS performed the experiments and generated data. MKR provided the gene construct. MVR, SS, and TK analyzed the data, and corrected and edited the manuscript. All the authors approved the final manuscript.

\section{REFERENCES}

Arnon, D. I. (1949). Copper enzymes in isolated chloroplasts. Polyphenoloxidase in Beta vulgaris. Plant Physiol. 24, 1-15.

Ashour, A., El-Sharkawy, S., Amer, M., Bar, F. A., Katakura, Y., Miyamoto, T., et al. (2014). Rational design and synthesis of topoisomerase I and II inhibitors based on oleanolic acid moiety for new anti-cancer drugs. Bioorg. Med. Chem. 22, 211-220. doi: 10.1016/j.bmc.2013.11.034

Ashour, M. E., Atteya, R., and El-Khamisy, S. F. (2015). Topoisomerase-mediated chromosomal break repair: an emerging player in many games. Nat. Rev. Cancer 15, 137-151. doi: 10.1038/nrc3892

Badaracco, G., Plevani, P., Ruyechan, W. T., and Chang, L. M. (1983). Purification and characterization of yeast topoisomerase I. J. Biol. Chem. 258, 2022-2026.

Bates, L. S., Waldren, R. P., and Teare, I. D. (1973). Rapid determination of free proline for water-stress studies. Plant Soil 39, 205-207.

Blattner, F. R. (2016). TOPO6: a nuclear single-copy gene for plant phylogenetic inference. Plant Syst. Evol. 302, 239-244. doi: 10.1007/s00606-015-1259-1

Capranico, G., Marinello, J., and Baranello, L. (2010). Dissecting the transcriptional functions of human DNA topoisomerase I by selective inhibitors: implications for physiological and therapeutic modulation of enzyme activity. Biochim. Biophys. Acta Rev. Cancer 1806, 240-250. doi: $10.1016 /$ j.bbcan.2010.06.003

Champoux, J. J. (2001). DNA topoisomerases: structure, function, and mechanism. Annu. Rev. Biochem. 70, 369-413. doi: 10.1146/annurev.biochem.70.1.369

Chen, T. H., and Murata, N. (2008). Glycinebetaine: an effective protectant against abiotic stress in plants. Trends Plant Sci. 13, 499-505. doi: 10.1016/j.tplants.2008.06.007

Choi, D. G., Hwang, J. S., Choi, S. C., Lim, S. H., Kim, J. G., and Choo, Y. S. (2016). The effect on photosynthesis and osmotic regulation in Beta vulgaris L. var. Flavescens DC. by salt stress. J. Ecol. Environ. 39, 81-90. doi: 10.5141/ecoenv.2016.009

Chomczynski, P., and Sacchi, N. (1987). Single-step method of RNA isolation by acid guanidiniumthiocyanate-phenol-chloroform extraction. Anal. Biochem. 162, 156-159. doi: 10.1016/0003-2697(87)90021-2

Corbett, K. D., and Berger, J. M. (2004). Structure, molecular mechanisms, and evolutionary relationships in DNA topoisomerases. Annu. Rev. Biophys. Biomol. Struct. 33, 95-118. doi: 10.1146/annurev.biophys.33.110502.140357

Dar, M. I., Naikoo, M. I., Rehman, F., Naushin, F., and Khan, F. A. (2016). "Proline accumulation in plants: roles in stress tolerance and plant development," in Osmolytes and Plants Acclimation to Changing Environment: Emerging Omics Technologies, eds N. Iqbal, R. Nazar, and N. A. Khan (New Delhi: Springer), $155-166$.

Doyle, J. J., and Doyle, J. L. (1990). A rapid total DNA preparation procedure for fresh plant tissue. Focus 12, 13-15.

Gadelle, D., Filée, J., Buhler, C., and Forterre, P. (2003). Phylogenomics of type II DNA topoisomerases. Bioessays 25, 232-242. doi: 10.1002/bies.10245

Grieve, C. M., and Grattan, S. R. (1983). Rapid assay for determination of water soluble quaternary ammonium compounds. Plant Soil 70, 303-307.

Hasanuzzaman, M., Alam, M. M., Rahman, A., Hasanuzzaman, M., Nahar, K., and Fujita, M. (2014). Exogenous proline and glycine betaine mediated upregulation of antioxidant defense and glyoxalase systems provides better protection against salt-induced oxidative stress in two rice (Oryza sativa L.) varieties. Biomed. Res. Int. 2014:757219. doi: 10.1155/2014/757219

\section{ACKNOWLEDGMENTS}

This work was funded by Department of Science and Technology (DST), New Delhi under the DST Young Scientist Fast Track Scheme to RJ. Financial assistance received from Department of Biotechnology (DBT), New Delhi and DST for research programmes (Grant No. SR/FT/L-70/2005) in MVR lab is acknowledged. The authors also acknowledge the support received through the DST-FIST programme, DU-DST PURSE grant and UGC SAP of the Department of Genetics, University of Delhi, South Campus.

Hazman, M., Hause, B., Eiche, E., Nick, P., and Riemann, M. (2015). Increased tolerance to salt stress in OPDA-deficient rice ALLENE OXIDE CYCLASE mutants is linked to an increased ROS-scavenging activity. J. Exp. Bot. 66, 3339-3352. doi: 10.1093/jxb/erv142

Heath, R. L., and Packer, L. (1968). Photoperoxidation in isolated chloroplast I. Kinetics and stoichiometry of fatty acid peroxidation. Arch. Biochem. Biophys. $125,189-198$.

Hernández, J. A., and Almansa, M. S. (2002). Short-term effects of salt stress on antioxidant systems and leaf water relations of pea leaves. Physiol. Plant. 115, 251-257. doi: 10.1034/j.1399-3054.2002.1150211.x

Hettiarachchi, G. H., Reddy, M. K., Sopory, S. K., and Chattopadhyay, S. (2005). Regulation of TOP2 by various abiotic stresses including cold and salinity in pea and transgenic tobacco plants. Plant Cell Physiol. 46, 1154-1160. doi: $10.1093 / \mathrm{pcp} / \mathrm{pci} 114$

Hsieh, T. S. (1990). 7 Mechanistic Aspects of Type-II DNA Topoisomerases. Cold Spring Harb. Monogr. Arch. 20, 243-263. doi: 10.1101/087969348.20.243

Kathiravan, M. K., Khilare, M. M., Nikoomanesh, K., Chothe, A. S., and Jain, K. S. (2013). Topoisomerase as target for antibacterial and anticancer drug discovery. J. Enzyme Inhib. Med. Chem. 28, 419-435. doi: 10.3109/14756366.2012.658785

Koca, H., Bor, M., Özdemir, F., and Türkan, I. (2007). The effect of salt stress on lipid peroxidation, antioxidative enzymes and proline content of sesame cultivars. Environ. Exp. Bot. 60, 344-351. doi: 10.1016/j.envexpbot.2006.12.005

Lai, S. J., Lai, M. C., Lee, R. J., Chen, Y. H., and Yen, H. E. (2014). Transgenic Arabidopsis expressing osmolyte glycine betaine synthesizing enzymes from halophilic methanogen promote tolerance to drought and salt stress. Plant Mol. Biol. 85, 429-441. doi: 10.1007/s11103-014-0195-8

Marrison, J. L., and Leech, R. M. (1992). Co-immunolocalization of topoisomerase II and chloroplast DNA in developing, dividing and mature wheat chloroplasts. Plant J. 2, 783-790. doi: 10.1111/j.1365-313X.1992.tb00147.x

Nitiss, J. L. (2009). Targeting DNA topoisomerase II in cancer chemotherapy. Nat. Rev. Cancer 9, 338-350. doi: 10.1038/nrc2607

Pyke, K. A., Marrison, J., and Leech, R. M. (1989). Evidence for a type II topoisomerase in wheat chloroplasts. FEBS Lett. 242, 305-308. doi: 10.1016/0014-5793(89)80490-9

Sakamoto, A., and Murata, N. (2002). The role of glycine betaine in the protection of plants from stress: clues from transgenic plants. Plant Cell Environ. 25, 163-171. doi: 10.1046/j.0016-8025.2001.00790.x

Sambrook, J., Fritsch, E. F., and Maniatis, T. (1989). Molecular Cloning, Vol. 2. New York, NY: Cold Spring Harbor Laboratory Press.

Santos, C. V. (2004). Regulation of chlorophyll biosynthesis and degradation by salt stress in sunflower leaves. Sci. Hortic. 103, 93-99. doi: 10.1016/j.scienta.2004.04.009

Šimková, K., Moreau, F., Pawlak, P., Vriet, C., Baruah, A., Alexandre, C., et al. (2012). Integration of stress-related and reactive oxygen species-mediated signals by Topoisomerase VI in Arabidopsis thaliana. Proc. Natl. Acad. Sci. U.S.A. 109, 16360-16365. doi: 10.1111/j.1365-313X.2011.04825.x

Singh, B. N., Mudgil, Y., John, R., Achary, V. M. M., Tripathy, M. K., Sopory, S. K., et al. (2015). Cell cycle stage-specific differential expression of topoisomerase I in tobacco BY-2 cells and its ectopic overexpression and knockdown unravels its crucial role in plant morphogenesis and development. Plant Sci. 240, 182-192. doi: 10.1016/j.plantsci.2015.09.016

Singh, B. N., Mudgil, Y., Sopory, S. K., and Reddy, M. K. (2003). Molecular characterization of a nuclear topoisomerase II from Nicotianatabacum that 
functionally complements a temperature-sensitive topoisomerase II yeast mutant. Plant Mol. Biol. 52, 1063-1076. doi: 10.1023/A:1025427700337

Singh, B. N., Sopory, S. K., and Reddy, M. K. (2004). Plant DNA topoisomerases: structure, function, and cellular roles in plant development. Crit. Rev. Plant Sci. 23, 251-269. doi: 10.1080/07352680490452816

Takahashi, T., Matsuhara, S., Abe, M., and Komeda, Y. (2002). Disruption of a DNA topoisomerase I gene affects morphogenesis in Arabidopsis. Plant Cell 14, 2085-2093. doi: 10.1105/tpc.001925

Tammaro, M., Liao, S., Beeharry, N., and Yan, H. (2016). DNA double-strand breaks with $5^{\prime}$ adducts are efficiently channeled to the DNA2-mediated resection pathway. Nucleic Acids Res. 44, 221-231. doi: 10.1093/nar/gkv969

Türkan, I., and Demiral, T. (2009). Recent developments in understanding salinity tolerance. Environ. Exp. Bot. 67, 2-9. doi: 10.1016/j.envexpbot.2009. 05.008

Vann, K. R., Ekiz, G., Zencir, S., Bedir, E., Topcu, Z., and Osheroff, N. (2016). Effects of secondary metabolites from the fungus Septofusidium berolinense on DNA cleavage mediated by human topoisomerase II $\alpha$. Chem. Res. Toxicol. 29, 415-420. doi: 10.1016/j.bmcl.2016.02.034

Vos, S. M., Tretter, E. M., Schmidt, B. H., and Berger, J. M. (2011). All tangled up: how cells direct, manage and exploit topoisomerase function. Nat. Rev. Mol. Cell Biol. 12, 827-841. doi: 10.1038/nrm3228

Vrielynck, N., Chambon, A., Vezon, D., Pereira, L., Chelysheva, L., De Muyt, A., et al. (2016). A DNA topoisomerase VI-like complex initiates meiotic recombination. Science 351, 939-943. doi: 10.1126/science.aad5196
Wang, J. C. (1971). Interaction between DNA and an Escherichia coli protein $\omega . J$. Mol. Biol. 55, 523-533.

Wang, J. C. (2002). Cellular roles of DNA topoisomerases: a molecular perspective. Nat. Rev. Mol. Cell Biol. 3, 430-440. doi: 10.1038/nrm831

Yin, Y., Cheong, H., Friedrichsen, D., Zhao, Y., Hu, J., Mora-Garcia, S., et al. (2002). A crucial role for the putative Arabidopsis topoisomerase VI in plant growth and development. Proc. Natl. Acad. Sci. U.S.A. 99, 10191-10196. doi: $10.1073 /$ pnas. 152337599

Yu, Q., Liu, J., Zheng, H., Jia, Y., Tian, H., and Ding, Z. (2016). Topoisomerase IIassociated protein PAT1H1 is involvedin the root stem cell niche maintenance in Arabidopsis thaliana. Plant Cell Rep. 35, 1297-1307. doi: 10.1007/s00299016-1961-7

Conflict of Interest Statement: The authors declare that the research was conducted in the absence of any commercial or financial relationships that could be construed as a potential conflict of interest.

Copyright (C) 2016 John, Ganeshan, Singh, Kaul, Reddy, Sopory and Rajam. This is an open-access article distributed under the terms of the Creative Commons Attribution License (CC BY). The use, distribution or reproduction in other forums is permitted, provided the original author(s) or licensor are credited and that the original publication in this journal is cited, in accordance with accepted academic practice. No use, distribution or reproduction is permitted which does not comply with these terms. 